\title{
Observations of supervisors and an actuarial research student on the qualitative research process
}

\author{
Jiajie Du, Aaron Bruhn (D), Bronwen Whiting \\ Research School of Finance, Actuarial Studies and Statistics, ANU College of Business and \\ Economics, Australian National University, Acton ACT, Australia
}

\begin{abstract}
We report on lessons and insights concerning an interview-based, qualitative research thesis undertaken by an honours year university student in actuarial studies, who had no previous experience with qualitative research. Motivations and the need for research of this nature are provided in depth. Observations are presented on key areas of the research process, from the perspective of both research student and supervisors. This informs future students who may be considering qualitative research, who have not previously engaged in this approach. It also informs supervisors in predominantly quantitative disciplines who may be unfamiliar with some of the nuances of interview-based approaches.
\end{abstract}

Key words: Actuarial education; Qualitative research; Reflective writing; Research process

JEL classification: I20, G22

doi: $10.1111 /$ acfi. 12377

\section{Introduction}

In this study, we provide a case study of relevance to an accounting and finance audience, in the form of lessons learned by an actuarial studies student undertaking a qualitative thesis. These lessons are relevant because actuarial education and practice have close links and overlap with various disciplines, such as accounting, with the education process for actuaries and accountants sharing various features, and facing similar challenges. For example, the

The authors thank all interview participants who contributed to this research. They also thank the Australian National University for the facilities and resources to enable this research to occur.

Please address correspondence to Aaron Bruhn via email: aaron.bruhn@anu.edu.au 
incorporation of generic, business-ready and communication skills in addition to respective core technical skills (e.g. see Shepherd, 2005; De Lange et al., 2006).

For this case study, we refer to a student (henceforth referred to as Alex) who conducted a qualitative thesis of 15,000 words as part of an honours year within a Bachelor of Actuarial Studies, at the Australian National University in 2016. Alex was a high-achiever in undergraduate study, and as would be expected of those undertaking actuarial studies, had particular strengths in quantitative and numerical analysis.

Alex's thesis investigated the strengths and weaknesses of the actuarial qualification process in Australia, by interviewing academic faculty in actuarial studies at seven universities. Alex identified that an 'ideal' education system could and should reflect various key features, including allowing for student characteristics and development over time; having clear goals with constructive alignment of assessments to those goals; and the promotion and development of generic skills as well as technical knowledge (see Ramsden, 1992; Biggs, 1999; Shepherd, 2005, 2010; Du, 2016). Alex used these features as a framework to assess the strengths and weaknesses of the Australian system for qualification as an actuary. By critically assessing insights from interviews, Alex was able to offer a meaningful contribution to the actuarial profession in the form of a peer-reviewed journal paper (see Du et al., 2017). His contribution is timely given the profession continues to review its own education system throughout 2018 and beyond.

We present a series of observations from both Alex and his two academic supervisors - one of whom is an actuary, and one of whom is a statistician (both have previous experience in qualitative research). In doing so, we offer the reflections of both the student and the supervisors on their own learnings during the research, particularly as it relates to the transition for Alex from a predominantly (and advanced) quantitative skill base up to the commencement of his thesis, to having to consider, conduct and then analyse findings from a predominantly qualitative methodology. Offering such 'reflection' is highly regarded in improving teaching practice ${ }^{1}$, so in a similar vein to Irvine and Gaffikin (2006), we offer analogous reflections on the research process.

This offers some practical lessons for those who may wish to explore questions of interest from a perspective and methodological approach that is new to them - particularly if moving from a background in quantitative analysis, to an interview-based qualitative investigation. Reporting on such lessons, including choices made and problems encountered, helps address the need for early researchers in particular to recognise and manage challenges within the research process (Abernethy et al., 1999). This discussion may also help motivate others to think of 'methodology' as a choice about what tools

\footnotetext{
${ }^{1}$ See, for example, the Higher Education Academy and ANU Education Fellowship Scheme at http://efs.weblogs.anu.edu.au/about/
} 
best meet the needs of a research goal, rather than as an allegiance to a familiar and default skill set. In other words, 'quant' and 'qual' need not be considered as awkward cousins, but merely as a package of approaches that are available to address questions of interest, as circumstances dictate.

We first motivate this study by briefly highlighting the value of research to the learning experience of university students, highlighting how the honours year experience in particular has not been subject to significant previous study. We then highlight the growing role of qualitative research in relevant business disciplines, such as accounting, finance and actuarial studies. We then provide an overview of the actuarial profession, and the actuarial education system, particularly in the context of Australia. We then present the personalised observations, reflections and learnings of Alex and supervisors, on each of seven key aspects of the research conducted: (i) motivation for the research topic; (ii) the process of gaining ethics approval; (iii) the choice of an interviewbased methodology; (iv) conducting the interviews; (v) analysing insights from the interviews; (vi) writing up the overall findings; and (vii) thoughts on the overall research outcomes. We then conclude.

\section{The value of research in university studies}

Various authors (e.g. Gardner, 2009; Stubb et al., 2012) have investigated the experience of doctoral students as a first encounter of university students with extensive and independent research. However, a growing body of work (e.g. Lopatto, 2010) shows the value of research for all students, particularly undergraduate students. Frequently, such research at the undergraduate level is either based on providing students with a semi-structured project or is conducted within a standard course as both an assessment and learning exercise - that is, a project within a one-semester course within a degree programme.

An honours thesis, however, does not fit either perspective particularly closely. It is more independently driven and of greater scope than a project within a course, yet of shorter duration and potentially greater intensity than a $\mathrm{PhD}$ thesis. ${ }^{2}$ The honours project, and indeed honours year, is a peculiarity of an English-style university system and has not been subject to wide study.

Furthermore, a standard business, accounting or finance degree ${ }^{3}$ programme typically contains a core research methods course, but in quantitative methods

\footnotetext{
2 At ANU, an honours thesis in actuarial studies consists of approximately 150,000 words (50 pages) and following the selection of a supervisor and topic, and presentation of research plan by late April, is predominantly conducted over 6 months for a submission date in October each year (alongside six full courses, five of which have the pressure of contributing to exemptions from professional actuarial exams). See https:// www.rsfas.anu.edu.au/rsfas-education/honours-in-rsfas/

${ }^{3}$ See, for example, see for example https://programsandcourses.anu.edu.au/2018/progra $\mathrm{m} / \mathrm{BCOMM}$
} 
only. And, despite a course in communication for business often being compulsory, qualitative research training is not. In addition, students exposed to research papers at an undergraduate level in these disciplines will potentially only see quantitative research papers in these interludes as well. Hence, a student in one of these disciplines could complete a standard 3-year Bachelor's degree with little training in reading, understanding or performing qualitative analysis. This is despite growing acknowledgement within some disciplines that qualitative research is valuable, and requires and develops a range of diverse skills that are valuable for not only research itself, but future vocational success (see, for example, Humphrey and Lee, 2004; Kaczynski et al., 2014).

Hence, given that research involvement has a role in improving learning outcomes for students; that qualitative research methodologies are novel for many students coming from predominantly quantitative (training and/or research) backgrounds; and that perspectives of research supervisors postresearch are not often publicly promulgated, this paper contributes a new perspective for this previously understudied student (honours) group. Thus, it also helps inform researchers from quantitative business disciplines who may consider engaging with this combination of student profile and research methodology. We now discuss the features of qualitative research in more detail.

\section{Qualitative research}

Various qualitative researchers acknowledge that in disciplines such as accounting and finance, research is understood by many as a predominantly quantitative undertaking, often involving large sets of data and empirical testing (Gippel, 2015b). As such, research success and acknowledgement has historically been difficult for research which does not adopt such approaches (Abernethy et al., 1999; Mills, 1999). The preclusion of such research 'success', on the basis of not fitting a particular research paradigm, contrasts with a view that academic research should have openness to new perspectives and practices (Parker, 2012).

Whereas quantitative research is viewed as rigorous by many due to its orientation to generate evidence on a large scale, with respect to a specific issue (Lodhia, 2017), a range of critiques have been raised in respect of qualitative research. This includes the presence of bias within the research process - such as selection of data sources, views of participants, conduct of interviews or collection of other data, coding of data, and interpretation of the data (McAlexander and Scammon, 1988; Abernethy et al., 1999; Mills, 1999; Shank, 2002; Flyvberg, 2006; Eisenhardt and Graebner, 2007; Marshall and Rossman, 2010; Broadbent and Unerman, 2011). As such, demonstrating validity and rigour in the research process provides a challenge for qualitative researchers (Abernethy et al., 1999; Mills, 1999; Gippel, 2015a), which is accentuated by the fact that findings may not be reproducible (Kvale and Brinkmann, 2009). 
A lack of generalisation to a wider context or larger scale is also seen to limit the legitimacy of qualitative research (Gippel, 2015a), although Abernethy et al. (1999) notes that such generalisation is not always a goal of qualitative research. Rather, a 'tolerance for ambiguity' (Hill, 2007) can feature in qualitative research, highlighted by the reality that statements from interviews, for example, can often be ambiguous and contradictory (Kvale and Brinkmann, 2009).

Furthermore, the resources required for qualitative research to be conducted on a meaningful scale can be significant (Mills, 1999; Broadbent and Unerman,2011). Hence, if only a small research team is involved, choices may have to occur between breadth and depth of investigations (Abernethy et al., 1999), and having larger research teams to deliver on research goals may not be possible.

However, many authors address the above concerns, to varying degrees (e.g. Abernethy et al., 1999; Shank, 2002; Corbin and Strauss, 2008; Kaczynski et al., 2014). We do not attempt to do justice to all such authorship here, but note that a range of approaches are taken within the research process to promote quality and credibility - which, as Kaczynski et al. (2014) highlight, is a requirement of all research, not just qualitative. Such approaches include, amongst others: taking a systematic approach in data analysis; demonstrating a close adherence to the underlying data; data triangulation; member checking; electronic recording of interviews; data saturation; and prolonged engagement in the field (Stake, 1995; Mills, 1999; Eisenhardt and Graebner, 2007; Freeman et al., 2007; Hill, 2007; Lodhia, 2017). Of note, even case studies of small (even single) sample size can be seen as providing some useful insights, particularly if additional perspectives outside a single research participant are referred to (Dapiran, 2016; e.g. in our case via the observations of student and supervisors).

As such, a steady stream of relevant papers has emerged in recent years that have used, or addressed the use of, qualitative research methodologies in accounting, finance or actuarial related areas (e.g. Sahi et al., 2013; Kaczynski et al., 2014; Bruhn, 2015; Cheah et al., 2015; Gippel, 2015a,b; Ho, 2015; Neck, 2015a,b; Salmona et al., 2015; Foster and Warren, 2016; Lodhia, 2017). Such papers describe the particular and situation-specific research rationale and methodology and provide a selection of approaches to verify and demonstrate validity of both method and findings.

There is also a call for more qualitative research in such disciplines. One reason is for greater diversity in research approaches, as part of providing a variety of methods to address a variety of research questions (Abernethy et al., 1999). This can provide flexibility in a world which is complex and constantly changing (Kaczynski et al., 2014; Salmona et al., 2015) and in doing so, can also provide a complement rather than competition to quantitative approaches (Lodhia, 2017). For example, qualitative research could work as a prelude to traditional empirical research (Kaczynski et al., 2014), or it could address questions and situations in a manner which are not captured by quantitative methods (Broadbent and Unerman, 2011). 
Qualitative research also has the potential to explore important issues in depth, within the context of a particular situation. This is particularly enabled through prolonged field work, or interviews (Eisenhardt and Graebner, 2007; FSA, 2009; McAlexander and Scammon, 1988; Patton, 2002). Lodhia (2017) highlights that such research can encourage conversations and dialogue amongst communities related to the research process, and Parker (2012) goes as far to say that a strong qualitative research community can potentially invigorate accounting research.

\section{Actuarial education}

An actuary belongs to a professional body that trains and enables them to 'evaluate risk and opportunity', by measuring and managing 'the financial implications of future events'. ${ }^{4}$ The requisite core knowledge includes the time value of money; dealing with contingent risks and probabilistic events; and understanding in depth a particular context such as insurance. As for any profession, education is a key component of attaining relevant skills - indeed, 'it is an essential requirement for a profession that it maintains the level and quality of knowledge of its members' (Daykin, 2005).

In Australia, the relevant professional body is the Actuaries Institute. To attain the professional designation of being a Fellow of the Institute (FIAA), a 3-part qualification pathway based on formal, exam-based education must be successfully completed:

- Part I consists of eight technical subjects, which can be attained through high grades in relevant courses within a degree programme at one of seven accredited Australian universities ${ }^{5}$, or via examinations directly through the UK Institute and Faculty of Actuaries (IFoA);

- Part II focusses on the principles of actuarial management as well as professionalism, and can only be attained via high grades in certain (usually postgraduate) courses offered through accredited universities;

- Part III includes four professional exams, with specialisation required with a choice of 2 of those 4 exams in either life insurance, general insurance, investment management and finance, or global retirement income systems.

A range of papers in recent years have discussed and presented evidence of the strengths and weaknesses of the actuarial education programme (Shepherd, 2005, 2010; Butt et al., 2014, 2016; Bruhn et al., 2017a,b). Shepherd (2010)

\footnotetext{
${ }^{4}$ See https://www.actuaries.asn.au/becoming-an-actuary, and https://www.soa.org/Ac tuarial-Profession/Actuary/risk-professional.aspx, respectively.

${ }^{5}$ The Australian National University, Bond University, Curtin University, Macquarie University, Monash University, the University of Melbourne, and the University of New South Wales.
} 
highlights that actuarial education 'gives undue emphasis to the technical at the expense of all the other dimensions of practice in a super-complex world' (p.16), and calls for a 'return to learning that is actively based on inquiry, discovery, articulation and communication, rather than passively based on receiving, imitating and reproducing' (p.16). In addition, as assessment 'defines the actual curriculum' from the perspective of students (Ramsden, 1992), Shepherd (2005) suggests that assessment should 'provide opportunities for the development of writing skills, oral communication skills, creativity, selfawareness, responsibility and self-assessment skills' (p.14). This also reflects previous observations on education for accounting graduates (De Lange et al., 2006). Without such skills, challenges exist for high-achieving but predominantly quantitatively-minded students, as they progress into more qualitative, open-ended, and 'contextual' questions in later exams and the workforce.

\section{Dialogue and reflections}

We now present the perspectives and reflections of Alex and the research supervisors, on each of the seven key aspects of the research process. This is not intended to be comprehensive in terms of all aspects of a research 'journey'. Instead, it presents the main insights and lessons learned from both student and supervisors, in this particular case. We begin with the overall motivation for the research topic.

\subsection{Motivation for the research topic}

\subsubsection{Alex}

The reason for choosing a research topic on actuarial education was mainly driven by my perceptions regarding part I of my undergraduate education. When doing part I, and completing those initial eight technical exams, I always wondered what actuaries do in real life. At that time, I felt that I would be less prepared for my further study and future career if I did not have a better sense of the practicality of the profession. Thus, I was incentivised to review the current actuarial education system as it would also give me insights about the overall purpose of all three parts, and how my future study might demand different skills to what I had learned up to this point in time.

In addition, my supervisors suggested that doing the research from an educator's perspective could be interesting, because reviews of professional education were seldom done exclusively from that point of view. This got my attention because as a recent actuarial graduate, I might be able to share some useful suggestions and thoughts based on my own 3 years of study (Part I) and my concurrent study of Part II. So, after some to-ing and fro-ing of ideas with supervisors, my research topic refined down to focus on actuarial educators' viewpoints about the education system itself. 


\subsubsection{Supervisors}

We are both, what might be termed, 'keen educators', who see teaching and education as a major attraction of our University role, rather than a hindrance to other academic priorities such as research. Our collective contribution to education includes policy and operational involvement in professional actuarial education beyond university study, a leadership (Deputy Dean) position in College-level education, and long-term experience as a programme convenor. From this experience, we are acutely aware that actuarial education in its entirety (both inside and outside the University setting) has been subjected, quite rightly, to a range of recent critiques (e.g. see Shepherd, 2005, 2009; Butt et al., 2014, 2016). Such critique has led to some calling for changes to the way education is delivered (e.g. see Shepherd, 2010; Chu et al., 2011). Such calls do not generally seek a decrease in the technical skills required to be an actuary, but rather to focus on developing such skills in the context of real-life applications, including greater use of peer review, group work, and open-ended rather than closed problems.

Given that the recent critiques look at the education system from the perspective of students, we considered that insights from the perspective of educators would be a complementary and constructive addition to this discussion - particularly as research into professional education is relatively scarce (Butt et al., 2014). Pursuing an investigation into education, which has professional implications, also seemed to be a responsible direction to direct our own research efforts (and aligns with Lodhia's (2017) call for research to be meaningful). This is because education is highly significant for any profession, in that it helps define what that profession is. For example, Daykin (2005) highlights the importance to a profession, of maintaining the quality of education of prospective members. It is also good practice to seek ways to improve any service over time, education included.

Alex was also the first research student that either of us had supervised, to use an entirely qualitative research methodology despite having a quantitativelyfocussed undergraduate degree. Hence, it was also of interest to us to see how he would deal with far more open and ill-defined issues in the form of competing ideas and opinions, through a qualitative lens, a challenge which Alex realised would be different to what he had previously encountered. This might also then provide a repository of lessons from Alex, to any future student who faces similar challenges in undertaking qualitative research.

\subsection{The process of gaining ethics approval}

\subsubsection{Alex}

I had not previously conducted research that dealt directly with human subjects, so I first had to get approval from our University's human ethics 
research committee. Before doing so, I attended a 2-h information and training session, which was useful as it made me think about important issues of preserving confidentiality of participants, and framing research in a way to keep the risk of accidental identification of specific participants to a minimum. These were things I had not previously needed to think about within my studies.

The subsequent process of getting research approval from the human ethics office went more poorly than I was anticipating, for various reasons. Firstly, I did not source and use the most up-to-date template for the overall application, which was simply an oversight of not looking hard enough at the relevant material on-line. Secondly and later in the process, my application was delayed, for reasons such as not providing the protocol number, not following the required format, missing certain information, not explaining things well, and so on. I realised that after three occasions of the human ethics office returning the overall written application to me, that I was not portraying a particularly professional approach, which I look back on with some disappointment. Although much of the ethics application was discussed in general with my supervisors, the first couple of times I sent it in for approval without getting their comments on the detail.

My shortfalls and frustrations in this process taught me an invaluable lesson - the importance of getting approval and feedback before taking actions, where possible. Ironically, doing so approach mimics much of what we are taught in part II actuarial subjects (which I was studying concurrently with the research), whereby appointed actuaries consider and/or approve any changes to matters of pricing, reserving, capital requirements and reinsurance arrangements prior to those things occurring. The analogy to my research is that I now see that although the approval process might take time and effort, it is actually meant to empower you and your research. It helps you consider multiple factors and perspectives, allowing you to proceed with confidence that others with more experience have peer-reviewed and aligned the research approach with more appropriate standards than what I started with.

In hindsight, I appreciated the rigour applied by the human ethics office. Their feedback highlighted that I was doing a serious research project, which needed to abide with established guidance.

\subsubsection{Supervisors}

In terms of the ethics process, we gave some thought to two possible supervisory approaches. Firstly, letting Alex drive the process as far as he was comfortable, or alternatively, taking a more nurturing, parental type approach. Given Alex's demonstrated high achievement and the high levels of energy he was bringing to the research, we favoured letting him do as much of it himself, so as to allow opportunity to demonstrate initiative, energy and proactivity with what was an unfamiliar task - with us just providing some guidance on the process. 
The decision between those two positions was also made to some extent for us, with Alex drafting and submitting ethics application(s) before getting detailed supervisory feedback. With the benefit of hindsight, whilst our admiration of his enthusiasm remains undiminished, the second series of feedback from the human ethics committee, which pointed out omissions and inadequacies in his proposal, could have prompted us to step in and exercise our role more deliberately. This would have had the twin benefits of ensuring Alex did not get more frustrated and demonstrating to the human ethics committee that the proposal was being taken seriously and professionally.

Perhaps the best learning for us as supervisors is that whilst it is certainly good (and ideal) for research students to have freedom and opportunity for initiative within their research, it is also of much benefit to ensure a process exists for feedback at key stages. On this note, it is encouraging to see Alex's own reflections on this matter and also to see him relating it to his other courses, with benefits in seeking advice and not hurriedly proceeding beyond what you are currently equipped for. Getting such feedback can and should be an important tool to assist planning and provide improvement.

\subsection{The choice of an interview-based methodology}

\subsubsection{Alex}

Finding out people's perceptions lends itself naturally to a qualitative research method, for which one tool is interviewed. I also considered a survey, which can be considered as qualitative where questions are open-ended.

I preferred an interview approach over a survey approach, for many reasons. Firstly, the number of lecturers in actuarial studies and who are actuaries themselves is quite small in Australia (approximately 30 in mid-2016). Hence, a small sample may not lend itself to a survey method where it has a goal to draw out meaningful statistical analysis. Secondly, although a survey can be completed more conveniently in many cases, it lacks the opportunity to ask respondents about their thoughts beyond the set questions. In comparison, an interview is a set time commitment of 45-60 min, but the interviewer can communicate more strategically with the interviewee. For example, when a general question like 'how do you feel about Part I education?' is asked, the respondent usually provides a few thoughts. Each of these might each lead to extra ideas and insights from the interviewees, with the interviewer then having to make a trade-off, by reducing time allocated to other questions, to allow for this new exploration. As I anticipated that participants would likely have a variety of opinions about the education system which would be difficult to exhaustively cover within a survey format, an interview method was preferred.

Nevertheless, to encourage participation, when contacting possible participants I offered a choice of how they could participate - via a verbal interview, or a written questionnaire. The use of focus groups was also briefly considered 
but logistical issues involving the amount of time required, the coinciding of available time, geographical separation, and costs of providing an experienced focus group facilitator, meant that this was not considered further.

\subsubsection{Supervisors}

Alex quickly assessed the various approaches open to him of interviews, surveys, and focus groups. He saw that interviews are a convenient way to explore the perceptions of others (as Stake (1995) points out), and can be used to keep responses relevant to the intent of the research goals (as Ospina (2004) points out). The choice of interview method is also supported by the fact that various other studies in the broader realm of financial services are similarly based on an interview approach (e.g. FSA, 2009; Foster and Warren, 2016).

At this stage of the process, Alex also began to talk with us about other key issues involved with conducting interviews, such as being aware of one's own biases, which can be mitigated to some extent using open-ended questions. This gives interviewees some discretion to focus on what they consider important (Mathers et al., 2002; Ospina, 2004). Alex discusses this in the next section.

We also considered that interviews were an appropriate approach, and aligned with the ideal of having research goals drive the methodology (Abernethy et al., 1999; Flyvberg, 2006; Broadbent and Unerman, 2011; Kaczynski et al., 2014; Lodhia, 2017). What was particularly interesting was to observe and help direct Alex, as a highly achieving 'quant', to manage and reflect on the research process, which this article helps him articulate further.

\subsection{Conducting the interviews}

\subsubsection{Alex}

After getting ethics approval to conduct interviews, I contacted possible participants from a list of thirty actuarial lecturers around Australia (of which 25 were Fellows of the Actuaries Institute). It might sound straightforward, but sending out 30 individual email invitations and then keeping on top of responses did mean I had to keep careful documentation, with some of those contacted answering promptly, and others not so promptly. Keeping a separate and dedicated folder in my email account helped have a clear and easily accessible history of communication with all contacts.

Thirteen of those contacted agreed to participate. Five agreed to a face-toface interview, seven agreed to a phone interview, and one agreed to do a written interview in the form of a questionnaire. The twelve nonwritten interviews each ranged from $45 \mathrm{~min}$ to $1 \mathrm{~h}$.

I felt that face-to-face interviews were far more effective and manageable than phone interviews, for two main reasons. Firstly, there was real benefit 
with the presence of body language and facial expressions within face-to-face interviews. For example, if a respondent was not interested in the topic, they might raise their eyebrows and start with an expression similar to, 'well.... If this occurred, I could adjust the discussion, to get the most out of the interview. Secondly, the performance of phone interviews was highly dependent on the quality of the phone connection. One interview had a problem as I could hardly hear the interviewee's voice. Thankfully, that interview was recorded and hence I could still capture 90 percent of the conversation, through repeated listenings. This taught me another lesson in that, if the quality of the call is bad, I need to be bold enough to politely explain and restart the call. However, this was not the easiest thing to do as I realised it could cause some frustration for interviewees whose participation was, of course, voluntary.

What did not work so well was the written interview/questionnaire. This participant did not have time for a phone interview, and hence I sent them a written list of my indicative interview questions. Perhaps due to their own time limitations, the responses were brief with only 'yes' or 'no' given to most questions. I then realised that questionnaires should be constructed quite differently to questions used as prompts for interviews, and again should have checked more deliberately for guidance on this from my supervisors before conducting something different to what I was used to.

I found that an important skill for interviews is writing key points during the interview. Writing down key words and thoughts as 'live' prompts to link with my intended topics was helpful because it might help the interviewee understand future questions more quickly, and give them a sense of familiarity and flow to the overall interview. Writing key points down is possible rather than trying to capture everything the interviewees have said, as I also used an electronic recording device for later partial or full interview transcription.

It was also useful to take a semi-structured approach to interviews. I first asked relatively general questions, to understand which kind of topics they have already thought of and what topics interested them. Then, according to their interest, I could ask them more detailed and specific questions. Although before each interview I had a list of points that I intended to discuss, they were best seen as a guide to help me decide the amount of time and focus allocated to different questions and topics. This is a good way to conduct interviews and is one definite advantage over surveys.

Time management was another issue. Usually, I spent 15-20 min on the first part of each interview, which involved asking general questions. However, two enthusiastic interviewees spent almost $40 \mathrm{~min}$ on this first part - which meant I later ran out of time to cover all specific questions that I wanted to ask. Communication is clearly an art which needs practice, as sometimes it is hard to politely change the direction of a conversation. In subsequent interviews, I prioritised later questions and deliberately spent less time on the first section of the interview. 
I also learned to deal with pauses in conversations, which sometimes involved thanking the interviewee for their comment when there was a noticeable pause. I noticed two types of conversational pauses - one long, and one short. A short break of usually 2-3 s was used to take a deliberate pause for breath or recall things from memory. However, a longer break of 5-s or more was used to think of some extra points that required something more than instantaneous replies, and/or involved something that they were unfamiliar with or hadn't considered in any depth before. If time allowed, it was then interesting to hear extra ideas, but if time was short, I preferred to concentrate on opinions that interviewees had spent time considering as I had sent interviewees a copy of the indicative interview questions prior to each interview.

After each interview, I would promptly write a summary of the interview and send this back to the interviewee. This was useful in checking and validating the correctness of my understanding of the interviewee's opinions and comments.

\subsubsection{Supervisors}

We observed that Alex's confidence grew over time. He seemed to find it particularly useful to write summaries of each interview promptly after each one, to benefit both his own learnings as well as having talking points to share with us in later meetings. It was very useful for him to electronically record each interview, despite this leading to another time-consuming step of transcribing and/or repeated listening to several interviews. He recognised that this approach of recording, re-listening, and getting participants to check his interpretation and recollection was a useful mitigation to his own potential biases and misinterpretations (see, for example, Marshall and Rossman, 2010).

Alex took the approach to first ask general questions about strengths and weaknesses of the actuarial education system, to give interviewees the opportunity to focus on those aspects that were of most interest to them. This is line with others who have researched via semi-structured interview techniques (e.g. Foster and Warren, 2016; Sahi et al., 2013; and see also Abernethy et al., 1999), and also suited what Alex was researching. Then, asking about specific aspects such as consistency between syllabus and assessments, gave interviewees additional freedom to express their comments on those and wider aspects in as much detail as they had given thought to. We also prepared Alex a little through practice interviews with each of us.

Alex did not discuss in depth with us many of his thoughts about the conduct or process of interviews themselves, but did discuss findings and insights he had from interviews. From such discussions, it was clear that he was picking up on the major education issues that we expected him to find. It was also clear that he was confident enough to interpret or view findings in lieu of his own thoughts about the education system. This made for interesting discussions about his own views, which changed over the course of the research - a good sign of real engagement with the research process. 


\subsection{Analysing insights from interviews}

\subsubsection{Alex}

Having recorded each interview electronically, I was able to review all interview content at any time. Originally, I planned to write an extensive summary of key insights from each interiew, but slowly recognised the benefit of listening to the whole recording again. Therefore, I chose to transcribe as much of the relevant conversation(s) as possible, so that I could easily cite this dialogue in the future.

The use of Microsoft Excel helped tabulate and categorise discussions from different interviews. This categorisation of discussions was a challenge, as I had to rely on my own subjective definitions and interpretation, which was initially quite unsettling. For example, a comment could be that it would be good to have universities provide professional exams in Part III, but universities just don't have the capacity to do that'. In this case, should I categorise this as supporting involvement of Universities in Part III education, or as a shortfall of university-based education in professional services? Such categorisation was subjective; therefore, also was the building up of a framework for reporting the key themes that emerged. Nevertheless, with the benefit of a having recorded dialogue of each interview, I could read each statement multiple times, to classify comments into similar themes as best I could.

Another challenge was how to draw useful conclusions, or to make suggestions to improve the education system, as there was a variety of opinions provided by interviewees. Usually, my recommendation followed the majority of my interviewees, such as assisting students with getting work experience or internships. However, I also supported minority opinions if they were aligned with what constitutes an 'ideal' education system based on my earlier literature search. One such example was my suggestion to make greater use of practical examples in the classroom.

I was also cognisant that I was assuming to a degree, that the opinions of thirteen respondents had some representativeness of all actuarial educators in Australia. Given the relatively small number of actuarial educators anyway, and that there was a likely selection effect to some degree with participants being those who have given some thought to the topic, I was reasonably comfortable that this assumption was not wildly unreasonable.

One key learning that I would pass to students who will do similar research in the future is to try to copy much of the interview dialogue down. There may not be a need to fully transcribe all conversations, but it is very useful to write down whole sentences of key discussions. Having such dialogue available means you can review them as many times as required, to make the soundest conclusion possible, based on readily available evidence in the form of quotations. Although this may take time initially, it saves time later when compared to going back and re-listening to original recordings that you may not 
immediately recall or know which part of an extended conversation was the most useful.

\subsubsection{Supervisors}

Alex came up with a framework to assess whether the current actuarial education system is robust and effective, in supporting the professional drivers and expectations of the actuarial profession. In doing so, Alex based insights on two things. Firstly, by weighing up and assessing often contrary opinions from interviewees. He conducted enough interviewees to pick up on the major pros and cons of certain parts of the education system and was able to think on the various opinions offered and then come up with his own picture of how things work and could be improved. This often meant siding with those views he had heard most frequently, but this was not exclusively the case. Secondly, by assessing insights in light of the background research he had done on what constitutes an 'ideal' education system. This meant that sometimes the views he heard less about were the ones he agreed with, if he judged that these views were aligned with what had made sense to him from his own background research and literature review.

In terms of process, his organisation and construction of argument improved as his thoughts consolidated over time. This offers some encouragement to others who may embark on similar research, as the early days can be obscure, confusing and unsatisfying, as nothing seems particularly concrete nor able to lend itself to any particular framework for understanding what can be complex questions. As for Alex though, as one's own understanding of the 'context' grows over time, clarity out of complexity is possible.

We imagine that Alex would now be surprised about how much clearer his thoughts are on actuarial education, as compared to what they were at the commencement of his research.

\subsection{Writing up the overall findings}

\subsubsection{Alex}

I found it very natural and useful to cite extended, word-for-word dialogues from interviewees when writing up my thesis. This was useful for several reasons - one being that because I found it a challenge to make a judgement about both appropriate classifications of comments, and of the 'rights' and 'wrongs' of certain views, then letting readers make a judgement themselves whether they agree with me or not was best served by providing as much context for comments as possible - which most easily came from the words of participants themselves. Word-for-word citations provided excellent 'contextual' evidence in this regard. It was also useful to demonstrate links between differing points made, as we may like to categorise 'points' as separate things in 
some deductive fashion, but of course this is not necessarily how people work or think in reality. I also found that reading participants' words makes for easier reading in other papers, so wanted to replicate that in my thesis.

Another key thing I learned is that, when you are writing an academic research report, you are best to treat your own views as those derived from the research itself and to take care with assuming too much. I was an actuarial student writing about actuarial education, which naturally means that I have my own opinions about the education system. As such, I started writing with expressions such as 'I think that....', and looked for evidence in relation to my thinking. However, my supervisors quickly pointed out that it is more convincing and informative to have insights, conclusions and recommendations starting from the research (background literature and interviews) itself. Although within discussion and conclusions I can certainly add in some of my own perceptions, they are a supplement to, rather than a basis for, research findings. Research findings need to be found in research, not oneself, otherwise it is not really research. This made sense to me, but I was surprised by how I could have constructed a case based on my views as a starting point rather than keeping a level of objectiveness and unbiasedness as much as possible.

\subsubsection{Supervisors}

It is challenge with interviews to distil insights down to a small number of themes or key points. In both spoken and written dialogue with us, Alex was very clear what views he was heading towards and why he was heading that way. As indicated above, he even changed his mind on some key issues (such as the appropriate timing within the overall education programme, of introducing 'soft' skills such as communication, versus 'hard' skills such as actuarial mathematics), which attested to us that his own thinking was changing not only in line with what he was hearing, but also in what he was processing and formulating as he was writing things down.

Alex's approach to present raw data in the form of interview quotations, to increase the assurance that what he understood was a reasonable deduction from what was said in interviews, aligned with good practice in qualitative research (see, for example, Shank, 2002; Eisenhardt and Graebner, 2007). As supervisors, it was encouraging to see him appreciate the practice used by others and to critically assess this practice in the light of his particular research topic.

From previous students' and our own experiences, we know the importance of avoiding procrastination when writing up a thesis - the longer it is left, the harder it gets, and the sooner you start, the more you realise that if you have worked hard, you should find plenty to write about and you will wish you started sooner. Alex did well here - he did not delay the writing up too long, had substantial drafts of the thesis ready in time for feedback to be given in an iterative fashion, was comfortable in presenting partially written sections for 
interim feedback along the way, he dealt with such feedback directly and openly, and yet still retained his prerogative to write what he wanted to write. This made for an enjoyable process of writing and review.

\subsection{Thoughts on the overall research outcomes}

\subsubsection{Alex}

In summary, my learning process in this research thesis was very positive. This related to both what I found out about my research topic, and to the research process itself.

In terms of the research topic, I can see now that from an educator's point of view, it is not straightforward to build up an education system that is suitable for every single student, as each student has different characteristics and learning styles. There are many factors to consider, such as trade-offs between teaching a strong theoretical and technical base, with that of using a more applied approach to help students be more adaptable to real-life practice in the future. There are practical realities to consider such as limited resources (time, staff, money), rapidly developing technology, and adherence to professional syllabus requirements, all of which are important factors, and which suggest educational challenges that I had not thought of before.

Despite my enjoyment of, and interest in the research, I do not consider that I could provide a focussed and insightful recommendation for improvement, to take the education system from its current state to an 'ideal' status. What I consider surprising about this, is that if at the commencement of the research I thought I would not have a firm conclusion at the end, then I would have been quite disheartened - but in reality, this outcome has not bothered me too much. In doing so, I have taken on board two key realities of actuarial work - that meaningful problems can be difficult to solve (and even understand), and that iterative steps towards something better may be more appropriate than immediate large changes. This reflects that what constitutes 'ideal' in education does not mean perfect solutions are available. If I was to follow up the thesis with additional research, I would increase my sample size, and extend to actuaries who are currently working in the industry. As one point of advocacy I made was to bring greater practicality into university actuarial education, it would be interesting to hear how employers in the field feel about this, and whether they would support such goals (e.g. by providing more internships and supervision on applied projects).

I have learned a lot from this research, and various skills have improved, including writing, reading, and communication skills. Slightly more nuanced skills include the ability to weigh up and summarise different opinions, and advocating and arguing for different ideas. I have since started an industry graduate role as an actuarial analyst, and see that the skills learned stand me in good stead for the future. 


\subsubsection{Supervisors}

Alex made a useful and novel contribution to an issue of some importance to a professional body. It was encouraging as supervisors, to see a high-achieving quantitative graduate extend his repertoire of skills into qualitative and essential more relational-based spheres, and to enjoy the process of doing so.

Alex achieved a good grade for his thesis, which contributed to gaining a first-class honours degree in what is a very challenging and selective discipline area. He also managed to have a summary of his thesis and findings published in an industry-relevant, peer-reviewed journal. Alex has thought about and suggested some natural extensions to his thesis, has a genuine interest in academic research at some stage in his career, and most definitely has a range of familiarity with and awareness of the benefits of research methodology that sits outside his own realm of having a predominantly quantitative focus.

\section{Summary of findings}

We present summaries of two aspects of the observations above. Firstly, a summary of the main insights upon which both Alex and research supervisors had strong common ground and cause to highlight. These are given in Table 1.

Secondly, there were two sets of insights for which there was less common ground between Alex and supervisors - not that this indicates such insights are controversial, but simply that they were the focus or in the mind of one party and not the other when reflecting about the research experience. The first of these saw Alex reflect on the challenges in analysing interviews, in terms of processes and techniques that could be used to help. In contrast, what supervisors highlight was Alex forming a framework to assist this process, within which such processes and techniques could contribute. In terms of writing up findings from interviews, Alex reflected on how the writing process helped change his views on what could be emphasised within actuarial education, whereas the supervisors highlighted Alex's diligence in writing up insights quickly.

\section{Conclusion}

In this paper, we have reported on the perspectives of both research student and research supervisors, concerning an interview-based, qualitative study into the strengths and weaknesses of actuarial education in Australia, as part of an honours thesis. The reported reflections covered seven key aspects of the research, and we find some common perceptions between the student and supervisors of how the research process unfolded. We also find, as might be expected, that the student and the supervisors emphasise some different lessons learned from the research process. This contributes to the literature as a reflective case study of a quantitatively trained student undertaking qualitative 
Table 1

Summary of insights from research student and supervisors regarding qualitative research

\begin{tabular}{|c|c|}
\hline Aspect of research & Insight from both research student and supervisors \\
\hline $\begin{array}{l}\text { Motivation for the } \\
\text { research topic }\end{array}$ & $\begin{array}{l}\text { It is important to choose a topic you have a genuine interest in; } \\
\text { Although having a 'personal' interest in the subject matter can introduce } \\
\text { some subjectivity into the research process, this need not be a barrier to } \\
\text { effective research }\end{array}$ \\
\hline $\begin{array}{l}\text { Process of gaining } \\
\text { ethics approval }\end{array}$ & $\begin{array}{l}\text { Getting advice from research supervisors is not a one-stop shop but rather } \\
\text { an ongoing process - close dialogue and supervision are needed when } \\
\text { considering new research approaches, particularly as it pertains to the } \\
\text { important issue of ethics }\end{array}$ \\
\hline $\begin{array}{l}\text { Choice of an } \\
\text { interview-based } \\
\text { methodology }\end{array}$ & $\begin{array}{l}\text { Interviews, surveys and focus groups each have different strengths and } \\
\text { weaknesses, for which the choice depends on the particular goals and } \\
\text { logistics associated with the research }\end{array}$ \\
\hline $\begin{array}{l}\text { Conducting the } \\
\text { interviews }\end{array}$ & $\begin{array}{l}\text { The interview process requires a high level of organisation, a plan with } \\
\text { flexibility, and communication skills more akin to 'art' than 'science'. }\end{array}$ \\
\hline $\begin{array}{l}\text { Analysing insights } \\
\text { from interviews }\end{array}$ & $\begin{array}{l}\text { Analysing interviews is challenging, and all such challenges should be } \\
\text { addressed rather than downplayed, including: } \\
\text { Subjectivity and judgement of the researcher, including their } \\
\text { interpretation of interview data; } \\
\text { Limits in the representativeness of the interview sample; } \\
\text { The probable lack of consensus in views expressed }\end{array}$ \\
\hline $\begin{array}{l}\text { Writing up the } \\
\text { overall findings }\end{array}$ & $\begin{array}{l}\text { Making raw data in the form of quotes has advantages for demonstrating } \\
\text { context; } \\
\text { It is important to explicitly show that data rather than preconceptions } \\
\text { have driven insights. }\end{array}$ \\
\hline $\begin{array}{l}\text { Thoughts on the } \\
\text { overall research } \\
\text { outcomes }\end{array}$ & $\begin{array}{l}\text { Research does not have to deliver definitive insights to be useful; } \\
\text { Highlighting how incremental improvements or understanding can be } \\
\text { made regarding the object of study, or simply learning new skills along } \\
\text { the research journey, are both worthwhile outcomes }\end{array}$ \\
\hline
\end{tabular}

research for the first time, together with observations of research supervisors, within the little-studied context of an honours degree in a business discipline.

Reporting such perceptions informs others who may pursue qualitative research in the future, particularly for those who are not familiar with interview-based approaches. It is apparent that those who are willing to learn and work at learning a new set of skills can successfully conduct research under an approach that was previously unfamiliar to them, and that, indeed, 'quants' can engage with 'qual' where the research goals demand it.

\section{References}

Abernethy, M. A., W. F. Chua, P. F. Luckett, and F. H. Selto, 1999, Research in managerial accounting: learning from others' experiences, Accounting \& Finance 39, $1-27$.

Biggs, J., 1999, What the student does: teaching for enhanced learning, Higher Education Research \& Development 18, 57-75. 
Broadbent, J., and J. Unerman, 2011, Developing the relevance of the accounting academy: the importance of drawing from the diversity of research approaches, Meditari Accountancy Research 19, 7-21.

Bruhn, A., 2015, Personal and social impacts of significant financial loss, Australian Journal of Management 40, 459-477.

Bruhn, A., B. Whiting, B. Browne, T. Higgins, and C. Tan, 2017a, Can universities hit the mark with specialist actuarial education? An initial ERM case study, Actuarial Research Clearing House 2017, 1-15 (Society of Actuaries).

Bruhn, A., B. Whiting, B. Browne, T. Higgins, and C. Tan, 2017b, Introducing enterprise risk management into the university classroom: a case study, Risk Management and Insurance Review 17, 99-131.

Butt, A., J. Evans, J. Farmer, and D. Pitt, 2014, A pilot survey of actuarial graduates' views on their education, Australian Journal of Actuarial Practice 1, 63-76.

Butt, A., J. Farmer, D. Pitt, and M. Salmona, 2016, A survey of actuarial graduates' views on their education, Australian Journal of Actuarial Practice 4, 35-49.

Cheah, K. K., F. D. Foster, R. Heaney, T. Higgins, B. Oliver, T. O'Neill, and R. Russell, 2015, Discussions on long-term financial choice, Australian Journal of Management 40, 414-434.

Chu, B. W. B., J. Evans, and D. E. Morgan, 2011, What perceptions do actuarial graduates hold on their university studies, work experience and career direction after completing the university program?, Australian School of Business Research Paper 2011ACTL12. Available at: http://papers.ssrn.com/sol3/papers.cfm?abstract_id = 2201217

Corbin, J., and A. Strauss, 2008, Basics of Qualitative Research: Techniques and Procedures for Developing Grounded Theory, 3rd edn (Sage Publications, Thousand Oaks, CA).

Dapiran, G. P., 2016, Can you do a case study based only on one interview?, Response to discussion thread on Research Gate. Available at: https://www.researchgate.ne t/post/Can_you_do_a_case_study_based_only_on_one_interview

Daykin, C., 2005, Actuarial education for the 21 st century, paper presented to the 13 th East Asian Actuarial Conference (EAAC), 12-15 September 2005, Bali, Indonesia. Available at: http://www.aktuaris.org/images/upload/File/11\%20Chris_Daykin_01. pdf

De Lange, P., B. Jackling, and A.-M. Gut, 2006, Accounting graduates' perceptions of skills emphasis in undergraduate courses: an investigation from two Victorian universities, Accounting \& Finance 46, 365-386.

Du, J., 2016, Applying the control cycle to actuarial education (Thesis for the degree of honours in actuarial studies, The Australian National University, Canberra, ACT).

Du, J., B. Whiting, and A. Bruhn, 2017, Views of educators on the education system, Australian Journal of Actuarial Practice 5, 107-121.

Eisenhardt, K. M., and M. E. Graebner, 2007, Theory building from cases: opportunities and challenges, Academy of Management Journal 50, 25-32.

Flyvberg, B., 2006, Five misunderstandings about case-study research, Qualitative Inquiry 12, 219-245.

Foster, F. D., and G. J. Warren, 2016, Interviews with institutional investors: the how and why of active investing, The Journal of Behavioral Finance 17, 60-84.

Freeman, M., K. deMarrais, J. Preissle, K. Roulston, and E. A. St. Pierre, 2007, Standards of evidence in qualitative research: an incitement to discourse, Educational Researcher 36, 25-32.

FSA (Financial Services Authority), 2009, Describing advice services and adviser charging, Report for the Financial Services Authority by IFF Research. Available at: http://www.fsa.gov.uk/Pages/Library/research/Consumer/index.shtml. 
Gardner, S. K., 2009, Special issue: the development of doctoral students-phases of challenge and support, ASHE higher education report, Volume 34, Number 6, 1-127, March 2009.

Gippel, J., 2015a, The masters of finance: ideas from the field, Australian Journal of Management 40, 557-561.

Gippel, J., 2015b, Masters of the Universe: what top finance academics say about the 'state of the field', Australian Journal of Management 40, 538-566.

Hill, L. H., 2007, Thoughts for students considering becoming qualitative researchers: qualities of qualitative researchers, Qualitative Research Journal 7, 26-31.

Ho, L., 2015, My boat my identity: investment in tuna fishing in Vietnam, Australian Journal of Management 40, 561-583.

Humphrey, C., and B. H. K. Lee, 2004, Real Life Guide to Accounting Research: A Behind-the-Scenes View of Using Qualitative Research Methods (Elsevier Science, New York, NY).

Irvine, H., and M. Gaffikin, 2006, Getting in, getting on and getting out: reflections on a qualitative research project, Accounting, Auditing \& Accountability Journal 19, 115145.

Kaczynski, D., M. Salmona, and T. Smith, 2014, Qualitative research in finance, Australian Journal of Management 39, 127-135.

Kvale, S., and S. Brinkmann, 2009, Interviews: Learning the Craft of Qualitative Research Interviewing, 2nd edn (Sage Publications, Thousand Oaks, CA).

Lodhia, S., 2017, What about your qualitative cousins? Adapting the pitching template to qualitative research, Accounting \& Finance [Epub ahead of print]. https://doi.org/ $10.1111 /$ acfi. 12266

Lopatto, D., 2010, Undergraduate research as a high-impact student experience, Peer Review 12, 27-30.

Marshall, C., and G. B. Rossman, 2010, Designing Qualitative Research, 5th edn (Sage Publications, Thousand Oaks, CA).

Mathers, N., N. Fox, and A. Hunn, 2002, Trent Focus for Research and Development in Primary Health Care: Using Interviews in a Research Project (Trent Focus Group, Sheffield, UK).

McAlexander, J. H., and D. L. Scammon, 1988, Are disclosures sufficient? A micro analysis of impact in the financial services market, Journal of Public Policy \& Marketing 7, 185-202.

Mills, A. M., 1999, A framework for the analysis of interview data from multiple field research sites, Accounting \& Finance 39, 79-105.

Neck, C., 2015a, Disappearing women: why do women leave senior roles in finance?, Australian Journal of Management 40, 488-510.

Neck, C., 2015b, Disappearing women: why do women leave senior roles in finance? Further evidence, Australian Journal of Management 40, 511-537.

Ospina, S., 2004, Qualitative research, in: G. R. Goethals, G. S. Sorenson, J. M. Burns, eds., Encyclopedia of Leadership (SAGE publications, Thousand Oaks, CA), 12791284. Available at: http://ualr.edu/interdisciplinary/files/2010/03/Qualitative_Researc h.pdf

Parker, L. D., 2012, Beyond the ticket and the brand: imagining an accounting research future, Accounting \& Finance 52, 1153-1182.

Patton, M. Q., 2002, Qualitative Research \& Evaluation Methods, 3rd edn (Sage Publications, Thousand Oaks, CA).

Ramsden, P., 1992, Learning to Teach in Higher Education (Routledge, London).

Sahi, S. K., A. P. Arora, and N. Dhameja, 2013, An exploratory inquiry into the psychological biases in financial investment behavior, The Journal of Behavioral Finance 14, 94-103. 
Salmona, M., D. Kaczynski, and T. Smith, 2015, Qualitative theory in finance: theory into practice, Australian Journal of Management 40, 403-413.

Shank, G. D., 2002, Qualitative Research: A Personal Skills Approach (Merrill/Prentice Hall, Upper Saddle River, NJ).

Shepherd, J., 2005, Hurdling or learning? An evaluation of the Australian actuarial qualification process, Paper presented to the Institute of Actuaries of Australia Biennial Convention, 8-11 May 2005, Cairns, Australia. Available at: http://actuarie s.asn.au/Library/Events/Conventions/2005/8.e-Shepherd_John_Final\%20Paper_Hud ling\%20or\%20learning_050413.pdf

Shepherd, J., 2009, What the student does - reflections on 25 years teaching actuarial students, Paper presented to the 44th Actuarial Research Conference, Society of Actuaries, 30 July-1 August 2009, University of Wisconsin, Madison, WI. Available at: https://bus.wisc.edu/ /media/bus/dp/academic-departments/risk-insurance/confe rence/conference-presentations/presentation-johnshepherd.pdf?la $=$ en

Shepherd, J., 2010, A blueprint for an actuarial education, Paper presented to the International Congress of Actuaries, 7-12 March 2010, Cape Town, South Africa. Available at: http://www.actuaries.org/EVENTS/Congresses/Cape_Town/Papers/ Education \%20\&\%20Professionalism/77_final\%20paper_Shepherd.pdf

Stake, R. E., 1995, The Art of Case Study Research (SAGE publications, Thousand Oaks, CA).

Stubb, J., K. Pyhältö, and K. Lonka, 2012, Conceptions of research: the doctoral student experience in three domains, Studies in Higher Education 39, 251-264. 